\title{
MÃES E FILHOS ESPECIAIS: REAÇõES, SENTIMENTOS E EXPLICAÇÕES À DEFICIÊNCIA DA CRIANÇA
}

\author{
Fabiola Brunhara \\ Eucia Beatriz Lopes Petean ${ }^{5}$
}

\begin{abstract}
RESUMO: O nascimento de uma criança deficiente traz nova realidade à família. O objetivo foi apreender quais reações, explicações, sentimentos e expectativas as mães exprimiam frente à notícia da deficiência do filho. A amostra caracterizou-se por 25 mães encaminhadas ao Aconselhamento Genético da FMRP- USP, entrevistadas individualmente sobre um roteiro semi-estruturado. Delas, 38\% estavam entre $20 / 25$ anos e $1^{\circ}$ grau incompleto (71\%). As crianças 52\% com até 1 ano. Os diagnósticos: $24 \%$ Síndrome de Down e $20 \%$ sem diagnóstico. Os dados - Análise de Conteúdo Temática - demonstraram que ao receberem a notícia as mães ficaram chocadas. Manifestaram sentimentos de negação, tristeza, resignação, revolta. Explicaram a problemática cientificamente e por crendices populares. Negaram a deficiência. Apresentaram expectativas à cura. Independente da problemática, a notícia choca. Há dificuldade em aceitar o diagnóstico e constante busca de cura. Os profissionais devem conhecer as condições emocionais lidando, assim, efetivamente com a realidade de cada família.
\end{abstract}

Palavras Chave: Família - Deficiência - Aconselhamento Genético

\section{MOTHERS AND SPECIAL SONS: REACTIONS, FELINGS AND EXPLANATIONS ABOUT CHILD DISABILITY}

\begin{abstract}
The born of child with disability give new reality to the family. The objective of this study was to determine the reactions, explanations, feelings and expectations the mothers present when notificated of the children disability. The study was conducted on twenty five mothers referred to the Genetic Counseling of the Faculty of Medicine de Ribeirão Preto - University of São Paulo. We used a semi-structural questionnaire. About the mothers, $38 \%$ aged between 20 to 25 years-old and $71 \%$ first incomplete degree. The children, $52 \%$ less than one year-old. Their diagnosis were 24\% Down's Syndrome and 20\% didn't have diagnosis. The data - qualitative analysis - demonstrated the emotional impact of the news was found to be as strong as a shock. Denial, sadness, resignation and revolt were some of the feelings experienced by the mothers. The explanation of the disability was from scientific aspects to popular belief. They expected theirs sons to be cured. Independently to the problem, the notification was the shock. To the mothers was difficult to accepted the diagnosis and found the cure indefatigably. The professionals have to known this emotional conditions to work effectively with the reality of every family.
\end{abstract}

Key words: Family - Disability - Genetic Counseling

O nascimento de uma criança com deficiência traz um nova realidade para a família. De acordo com MacCollum (1984) os pais experimentam a perda das expectativas e dos sonhos que haviam

\footnotetext{
${ }^{5}$ Endereço para correspondência : Eucia Beatriz Lopes Petean, departamento de Psicologia e Educação, Faculdade de Filosofia, Ciências e Letras da USP, Avenida Bandeirantes, 3900, Cep 14040-901, Ribeirão Preto, São Paulo, fone/fax (16) 6023730. E-mail ebpetean@ffclrp.usp.br
}

construído em relação ao futuro descendente.

A extensão e a profundidade do impacto deste nascimento são indeterminadas, depende da dinâmica interna de cada família e do significado que este evento terá para cada um (Faber, 1972).

No entanto, a família acaba procurando meios de se adequar à nova realidade. Desenvolvem duas maneiras de lidar com a informação: enfrentando e reagindo (Miller, 1995). Enfrentar significa fazer

Paidéia, FFCLRP-USP, Rib. Preto, junho/99. 
aquilo que é preciso, lidar com problemas e avançar. Reagir significa lidar com emoções que iñcluem desde confusão até o medo da incompetência.

Todos vivenciam o choque e o medo com relação ao evento ou ao reconhecimento da deficiência, bem como a dor e a ansiedade de se imaginar quais serão as implicações futuras. Todos experienciam a perda que gera desapontamento, frustração, raiva, à medida que desaparecem a liberdade e o tempo para o lazer (Vash, 1988).

Enfim, sentir-se responsável pelo problema do filho, conformado ou revoltado é uma forma de tentar elaborar o que deu errado. Assume-se a culpa, o conformismo e a raiva porque quando existe um culpado, ao menos existe uma explicação.

Ao contrário, os pais podem se defender simplesmente negando. A negação é um mecanismo de proteção amplamente discutida na literatura (Buscaglia, 1993; Petean, 1995; Petean \& Pina-Neto, 1998) Apresentando-se quase sempre de duas formas. A negação escolhida, caracterizada por um pensamento do tipo "se eu ignorá-la, talvez vá embora". A negação inconsciente quando realmente se olha para os fatos e não consegue percebê-los como verdadeiros (Miller, 1995).

Esses sentimentos e processos pelos quais passam os pais vão interferir diretamente na aceitação da criança. Os pais ao perderem o filho desejado podem, imersos em seu sofrimento e não elaborando o luto, estarem impedidos de estabelecer um vínculo com o bebê real. Podem fazê-lo, por exemplo, com o bebê desejado e perdido, ficando, assim, prisioneiros da melancolia. Ou podem, paradoxalmente, estabelecer o vínculo com a deficiência e não com o filho deficiente, ou seja, suas relações estarão baseadas no fenômeno e não na criança, nas práticas terapêuticas e não nas necessidades humanas (Amaral, 1995).

Torna-se, assim, de suma importância, a maneira pela qual os pais vão explicar a causa da deficiência de seus filhos - a compreensão do significado do problema.

Conforme vão superando e sobrevivendo à deficiência, começam a criar expectativas que vão de positivas à negativas. Esperam desde o desenvolvimento da criança até a completa incredibilidade em relação a situação do filho (Omote, 1980). É interessante notar que essas expectativas também podem ser influenciadas pelas explicações que constróem como causa da deficiência (Brunhara \& Petean, 1998). Independente da explicação que possuem, as mães esperam que o desenvolvimento do filho melhore ou seja normal. O desejo de cura é uma constante (Petean, 1995).

Para os profissionais envolvidos com as famílias de pessoas portadoras de deficiência, é de suma importância que tenham o maior conhecimento possível das dinâmicas pelas quais passam estas famílias para se instrumentalizarem emocional e racionalmente, uma vez que a literatura (Regen e cols., 1993; Omote, 1980; Petean, 1995; Petean \& Pina-Neto, 1998) tem enfatizado a necessidade de que esses pais recebam o maior número possível de informações, que tenham suas dúvidas esclarecidas para que possam decidir com maior segurança os recursos e condutas primordiais para o bom desenvolvimento de seu filho.

\section{Objetivo}

O objetivo desse trabalho foi o de apreender as reações, explicações, sentimentos e expectativas que os pais de crianças portadoras de deficiência exprimiam frente à notícia da possível deficiência e/ ou anomalia genética de seus filhos.

\section{Método}

\section{Sujeitos}

Foram entrevistadas vinte e cinco mães encaminhadas ao Serviço de Genética Médica da Faculdade de Medicina de Ribeirão Preto da Universidade de São Paulo para Aconselhamento Genético constando de diagnóstico, prognóstico e orientação. Destas mães, vinte e uma tinham filhos com suspeita de serem portadores de deficiência e/ ou anomalia genética. As outras quatro mães estavam sendo encaminhadas para diagnóstico de Futura Descendência, ou seja, situações em que o casal vem para Aconselhamento Genético, o filho afetado já faleceu e, portanto, o objetivo do estudo é especificamente determinar os riscos para futura descendência do casal (Pina-Neto, 1983). 


\section{Coleta de dados}

Tendo em vista os objetivos da pesquisa, de apreender dados relativos à sentimentos, percepções de experiências passadas dos sujeitos, dados que estão "dentro" dele e que de acordo com Cannell \& Kahn (1974) só ele é capaz de informar, optou-se por realizar entrevistas semi-estruturadas utilizando um roteiro com tópicos (temas ou núcleos) relacionados e direcionados para tais objetivos. O roteiro configurou-se por seis temas: dados pessoais; sobre o nascimento; informações sobre o serviço; conhecimento do problema; aspectos emocionais; e informações gerais sobre o casal.

As entrevistas foram realizadas por um profissional/psicólogo antes da primeira consulta médica no serviço.

\section{Análise dos dados}

Optou-se pela análise qualitativa uma vez que segundo Biasoli-Alves \& Dias (1992), "apesar de não desenvolver quantificação dos dados não perde com isso o rigor científico".

Para iniciar a análise - Análise Temática de Conteúdo - retoma-se os objetivos, realiza-se uma leitura exaustiva das entrevistas com o intuito de deixar-se impregnar pelo seu conteúdo. Nessa fase determinam-se os recortes, a forma de categorização, e os conceitos teóricos mais gerais para orientação da análise (Minayo, 1993).

Assim ficaram estabelecidos os seguintes recortes: reações das mães quando receberam a notícia da possível deficiência do filho; as explicações para o problema; os sentimentos vivenciados; e as expectativas quanto ao futuro. A seguir foram construídas as categorias e as mesmas foram então definidas.

De acordo com a forma de análise proposta, não houve a preocupação de quantificação dos dados em termos de frequiência. Assim, todas as categorias referentes aos temas serão apresentadas.

A Identificação das famílias foi realizada atribuindo-se números às mesmas, aleatoriamente, de um a vinte e cinco, e posterior diagnóstico da criança. Por exemplo: F1 -Síndrome de Beckwith-Wiedeman.

\section{Caracterização da Amostra}

A amostra caracterizou-se por vinte e cinco mães que foram encaminhadas ao Ambulatório de Genética Médica do Hospital das Clínicas da Faculdade de Medicina de Ribeirão Preto - USP. Destas mães, quatro não possuíam filhos pois vieram ao serviço para diagnóstico de Futura Descendência com histórico de abortos de recorrência. Da amostra total, $40 \%$ das mães tinham idade de 20 a 25 anos ao nascimento do filho afetado ou dos abortos; e $24 \%$ tinham idade de 25 à 30 anos. A maior parte, $72 \%$, apresentou nível de escolaridade de $1^{\circ}$ grau incompleto, seguido de $2^{\circ}$ grau incompleto, que teve uma porcentagem de $12 \%$.

Em relação às vinte e uma crianças, onze ou $52,38 \%$ da amostra chegaram ao Ambulatório com até um ano de idade, seguido de cinco crianças $(23,80 \%)$ com idade entre dois e três anos. Onze crianças são do sexo masculino $(52,38 \%)$ e dez $(47,62 \%)$ do sexo feminino. A ordem dos nascimentos demonstra que $32 \%$ delas são primogênitos, $28 \%$ segundos filhos, sendo que $16 \%$ das crianças quarto filho ou mais. Quanto ao planejamento da gravidez, da amostra, $60 \%$ das mães não planejaram engravidar do filho afetado.

Os diagnósticos definidos durante o Aconselhamento resultaram em cinco crianças $(23,80 \%)$ com Síndrome de Down, duas com Síndrome de Silver-Russel $(9,52 \%)$, duas $(9,52 \%)$ com hidrocefalia e também duas $(9,52 \%)$ crianças com Retardo do Desenvolvimento Neuro-PsicoMotor (RDNPM). Do total das crianças, quatro $(19,04 \%)$ permaneceram sem diagnóstico definido após um ano e meio de atendimento na genética.

\section{Resultados e Discussão}

A análise das entrevistas demonstrou que as mães reagiram a notícia da possível deficiência do filho intensamente. As reações eram concomitantes à notícia mas não seguiram uma ordem pré-estipulada, sendo que uma não excluía necessariamente a outra. As mães passaram por: 
Choque: "Quando a médica falou fiquei chocada. Fui ao telefone e liguei para ele (marido). Pedi para ele vir para o hospital." (F4 - Síndrome de Down)

O choque pode ser definido como um abalo emocional (Ferreira, 1988). Para Drotar (1975) é uma interrupção abrupta dos estados emocionais usuais, que rompe com o equilíbrio de cada um. É descrito como uma situação de torpor, uma sensação de impotência e sentimento de desamparo.

A análise dos dados das entrevistas demonstrou que qualquer dúvida levantada em relação às condições de saúde física e/ou mental da criança deixou as mães chocadas. Elas relataram esta reação aliando-a a sentimentos de perda e de pesar. Perda do filho sonhado e pesar pelo próprio desapontamento, pois se sentiam logradas ao direito do filho perfeito, ficando sem saber como proceder no momento da notícia.

Tristeza: "Fiquei triste, a gente estava preparado para uma coisa aconteceu outra... a gente esperava um filho perfeito, faz lembrancinhas, as pessoas vão visitar e ela (criança) não estava em casa." (F25 - Hidrocefalia)

A tristeza é um aspecto revelador de mágoa ou aflição (Ferreira, 1988). No momento da notícia, as mães disseram-se tristes, decepcionadas e frustradas frente à ausência da satisfação do desejo do filho idealizado. Como na amostra de Miller (1995) as mães lastimaram as mudanças concretas que estavam precisando fazer na sua vida. Outro aspecto importante é a "tristeza crônica", um sentimento que nunca é superado e frequientemente revivido: aniversários, idade de entrada na escola, etc., trazem à tona o que poderia ser e não é.

Resignação: "Deus quis assim a gente tem que se conformar... Se Deus quiser liberta ele" (F6 - Distrofia Muscular Progressiva Tipo Duschenne)

A resignação é encontrada como a renúncia espontânea de uma graça; a submissão paciente aos sofrimentos da vida (Ferreira, 1988). Apareceu acompanhada por sentimentos de passividade, de conformismo, de valores religiosos e misticismos. Pode estar influenciando na aceitação da criança e na visão que a mãe construirá da deficiência do filho. O risco se faz presente a partir da crença de que não há mais nada a se fazer pela criança omitindo-se, minimamente, aos tratamentos necessários.

Revolta: "a égua (médica) falou que ele (criança) tinha Down, que não ia andar, não ia falar. Quase bati nela, joguei pela janela..." (F4 Síndrome de Down)

A revolta, grande perturbação moral causada por indignação, aversão e repulsa (Ferreira, 1988) é uma reação manifestada frente a uma situação não esperada sobre a qual não se tem controle. Esta revolta foi expressa pela aversão à criança, ao cônjuge, à Deus, aos profissionais que estavam envolvidos com a família, enfim, à terceiros. Funciona como uma válvula de escape para a cólera que sentiram pela injustiça do problema de seus filhos.

Busca: "Quando fiquei sabendo, queria saber de tudo: risco de vida da criança, conseqüências, como a criança seria, quis conhecer a APAE..." (F19 - Hidrocefalia).

A busca resulta na necessidade de procurar respostas e formas de auxiliar frente à algo que incomoda ou requer cuidados. Boyd (1950), pai de uma moça excepcional, coloca a busca como uma etapa em que parou de pensar menos em si próprio, para passar a pensar em sua filha. Como as mães entrevistadas, começaram a apresentar necessidade de enfrentar a anomalia da criança, fazendo com que procurassem especialistas e instituições, ou seja, respostas aos seus mais variados questionamentos, crendo, assim, na volta de um certo controle para suas vidas.

Em relação à causa da deficiência, as mães buscam fundamentos científicos, religiosos e populares para explicá-la:

Científicas corretas: "os médicos falaram: um problema na hora que o espermatozóide encontra o óvulo. Aconteceu algo, deu um acidente" (F4 Síndrome de Down)

São respostas que se fundamentam nas Leis e Princípios aceitos na Biologia Humana e na Medicina (Pina-Neto, 1983). Foram as explicações que as mães ofereceram corretamente tais quais as explanações dos profissionais que lidam com a criança.

No entanto, observou-se que apesar das mães 
relatarem tais explicações, não deixaram de acreditar em seus próprios argumentos. Um dado que fala por si só é o da F9 (RDNPM): a mãe explicou a problemática da criança em termos científicos - "porque ele é prematuro, nasceu de 6 meses" - mas não deixou de colocar também como causa "porque quando estava com 4 meses caiu na creche e isso causou o problema" - resposta categorizada como Crendice Popular - demonstrando, assim, a força dos crenças pessoais de cada um.

Científicas incorretas: "ele (criança) é assim por ter sofrido várias cirurgias de hérnia intestinal." (F2 - Síndrome de Beckwith-Wiedemam).

São as explicações com fundamentos científicos verbalizados erroneamente, equivocadamente ou com terminologia incorreta (Pina-Neto, 1983). Essas explicações oferecidas pelas mães demonstraram a tentativa da procura de algo concreto e visível (características familiares comuns, problemas físicos palpáveis, dados da idade da mãe) que justificasse a deficiência. Aliadas a tais explicações vinham também embutidas expectativas concretas que sanassem a problemática da criança, como algum medicamento ou tratamento que melhorasse ou até mesmo curasse os traços da síndrome.

Castigo: "acho que o cigarro colaborou, sei lá, o organismo estava pré-disposto." (F1 - Síndrome de Silver-Russel).

As explicações não encontram fundamento nos princípios ou leis científicas, mas em princípios religiosos ou em algum ato condenável social ou cientificamente. As mães entrevistadas argumentaram a anomalia da criança em atos que executaram, reprováveis, que às levaram ser castigadas.

O castigo apresenta-se aliado ao sentimento de culpa. Quando as mães realmente cometiam algum ato, direta ou indiretamente, que julgavam errado ou que estavam contra as normas da sociedade em que viviam emergiram os sentimentos de autorecriminação e de remorso.

Crendice Popular: "Porque quando estava com 4 meses caiu na creche e isso causou o problema." (F9 - RDNPM).

São as explicações que não apresentam fundamentos em leis científicas ou princípios religio- sos, mas acham-se fundamentadas em conceitos enraizados na cultura popular (Pina-Neto, 1983). Demonstrou o processo mental que as mães construíram como hipótese da causa da deficiência da criança, corroborando a observação de que elas procuram algo concreto como explicação, que satisfaça, independente das curiosas associações que fazem.

Não sei: "não encontro explicação nenhuma, fico sem saber o que pensar." (F21 - Sem Diagnóstico).

As mães não conseguiram explicar a deficiência do filho. Demonstraram sentirem-se confusas e perdidas frente a tantas coisas novas que passaram à enfrentar.

Esse fato pode relacionar-se à complexidade das vivências que as mães devem estar experienciando. De um lado todo o jargão médico, exames, profissionais específicos para cada problema. Do outro lado sentimentos conflitantes e falta de controle, enfrentamento de novas realidades que promovem estresse, dor e tristeza, aliados ao amor e carinho que sentem pela criança e medo do que pode vir à acontecer.

Outra hipótese decorreu do sentimento de negação, uma vez que o que não existe não precisa ser explicado.

O tema sentimentos abarcou o que as mães estavam sentindo no momento em que foram entrevistadas, ou seja, qual sentimento estava ali presente resultante, principalmente, do enfrentamento da deficiência do filho.

Negação: "eu acho que não tem problema, o pai também era baixinho. A única coisa é que ele não engorda" (F13 - Síndrome de Silver-Russel).

A negação é encontrada como resultado de uma falta ou ausência (Ferreira, 1988). É uma atitude que encobre a não aceitação da deficiência, ou seja, a pessoa se recusa a enxergar a realidade como ela se apresenta, fantasiando ou fingindo que o problema não existe (Ardore e cols., 1988).

Decorrente dessa amostra, a negação da condição de deficiente do filho foi expressa de várias formas, explícitas ou implícitas. As mães: negaram a problemática da criança como um todo, como se esta simplesmente não existisse. Negaram baseadas no funcionamento fisiológico da criança, como se algo 
externo, cirurgias ou doenças congênitas, impedisse o organismo de se desenvolver. E negaram também baseadas nos traços físicos e/ou mentais, procurando na família traços que se assemelhem aos traços característicos da síndrome.

Este sentimento foi intenso sendo frequientemente relatado. Apresentou-se quase sempre aliado a todos os outros sentimentos manifestados.

Resignação: "não tem cura, ele (criança) tem (a deficiência) e pronto. Temos que ajudar ele..." (F4 - Síndrome de Down)

As mães entrevistadas relataram sentimento de resignação e de conformismo atrelados à princípios religiosos. Como no estudo de Vale (1997), esta categoria configurou-se por discursos que as mães não mostravam rancor e sentimento de impotência, ao contrário, apresentavam sentimento de que não esperavam mais nada da medicina, que fizeram e estão fazendo tudo que é humanamente possível, e que nesse momento só lhes resta extrapolar a situação terrena para buscar conforto num Ser superior.

Revolta: "A gente faz tudo que pode, repouso, parei de trabalhar para ter o filho... e aí a gente perde?" (F7 - Futura Descendência).

A revolta, perturbação moral causada por indignação, foi outro sentimento evidente. Os relatos da amostra indicaram a indignação que as mães estavam experienciando frente à deficiência da criança, verbalizando as várias perdas que sofreram, bem como as mudanças pessoais e a decepção frente ao ocorrido com o filho.

Observa-se que esse sentimento não foi estanque, alternando-se com sentimento de resignação. Essa dualidade demonstra claramente a turbulência do processo, levando as mães a situações de extremo conflito.

Premonição: "não sei, pensava sempre que ia nascer com problema." (F20 - Sem diagnóstico).

A premonição é definida como uma sensação ou advertência antecipada do que vai acontecer, um pressentimento (Ferreira, 1988). As mães entrevistadas relataram que sentiram, que de alguma forma haviam sido avisadas que estavam prestes à ter uma criança com problemas.

No entanto, Soifer (1980) alerta que toda gestante apresenta sonhos típicos da gravidez, que exprimem os temores em relação à maternidade e a incapacidade de criar e educar os filhos. No geral, a tendência é o de expulsar esses sentimentos. Porém, como no caso dessa amostra, quando nasce uma criança com problema o sonho torna-se realidade tomando a característica da premonição, passando as mães a associarem os fatos e a sentirem que foram avisadas que algo sucederia com o filho.

Discute-se também se a premonição não poderia se considerada um mecanismo de defesa. $O$ sentimento das mães de que algo de errado estava para acontecer com a criança foi concretizado, assim, não teria porquê se decepcionar com o ocorrido, uma vez que de alguma maneira haviam sido alertadas.

Confusão: "Estou com a cabeça atordoada... não consigo expressar o que estou sentindo, minha cabeça está toda enrolada..." (F3 - Síndrome de Down).

A confusão é a incapacidade de reconhecer diferenças ou distinções. É uma falta de clareza (Ferreira, 1988). As mães relataram conflitos com relação ao que estavam sentindo, uma vez que encaravam um fato inesperado com o qual tinham que lidar. É o sentimento de dúvida, expresso pelas mães, sob as mais variadas formas, no qual tudo lhes parece extremamente difícil. Ao mesmo tempo relataram a inquietação que sentem diante dessas dúvidas.

Segundo Reagen e cols. (1993) esse é um momento que de nada adiantam as informações dos profissionais uma vez que as mães demonstram-se bloqueadas emocionalmente e incapazes de absorverem-nas. Assim, elas passam a revelar muito mais dúvida e temor do que confiança em relação ao tratamento. Entretanto, ao mesmo tempo em que esse traz dúvidas e incertezas ele é tido em última instância como uma possibilidade de melhora e cura. È o momento que a mãe faz por fazer, no qual as questões emocionais apresentam-se de forma intensa.

Culpa: "O pai se sente culpado, ele (pai) fica calado, acho que ele pensa... que se sente culpado." (F14 - Futura Descendência)

A culpa é o sentimento de ter sido o responsável por uma ação ou por uma omissão prejudicial, reprovável ou criminosa. É a violação ou 
inobservância de uma regra de conduta, de que resulta lesão do direito alheio (Ferreira, 1988). As mães demonstraram através de seus relatos que se sentiram culpadas por atos que acreditavam serem os prováveis responsáveis total ou parcialmente pela deficiência do filho.

Como no estudo de Valle (1997), também nessa amostra, seguido à reação inicial de choque vem o sentimento de culpa. Implicitamente, as afirmações contêm também sentimentos de vergonha. Como diz Buscaglia (1993), os pais juntamente com o sentimento de pecado e repugnância pelo que fizeram, sentem-se indignos de terem o filho perfeito já que erraram. E esperam que seus filhos de certa forma se tornem um reflexo do melhor de si próprios, sentem-se envergonhados quando isso não acontece, principalmente se acreditam que esse não acontecer é fruto de algum ato que cometeram.

Os dados relativos às expectativas relatadas em relação ao futuro da criança apontam para alguns aspectos positivos, crendo no desenvolvimento da criança e na cura. As mães justificavam essas expectativas, demonstrando a capacidade de selecionarem os pontos que seus filhos podem estar desenvolvendo.

Positivas: "é uma criança que vai inspirar cuidados o resto da vida, mas eu espero que ela supere $e$ fique o melhor possivel..." (F25 - Hidrocefalia)

Expectativas Positivas foram compostas com as verbalizações que expressavam esperança de um futuro promissor para a criança portadora de deficiência. As mães relataram a necessidade de concretizarem o que idealizaram para seu bebê independente das dificuldades que possa apresentar. Petean (1995) relata que as mães tentam superar a problemática do filho valorizando as características físicas e de personalidade da criança. Atentam para as reais possibilidades em detrimento dos pontos tidos como prejudicados.

Desenvolvimwnto criança: "acho que ele (criança) vai recuperar o atraso... ele está indo bem..." (F2 - Síndrome de Beckwith-Wiedeman)

O desenvolvimento da criança foi visto como uma expectativa de progresso relativo tanto ao físico, quanto ao intelecto. As mães amostra esperam que seus filhos tornem-se maiores ou mais fortes, ou que progridam, aumentando sua capacidade intelectual.

Cura: "quando a gente procura o médico quer cura... “ (F21 - Sem Diagnóstico)

A cura é um meio de debelar uma doença, um tratamento (Ferreira, 1988). As mães mostraram a expectativa de sanar a problemática da criança, independente dos meios que levassem a este fim. Foi uma crença vocalizada livremente. Crepaldi (1999) relata que "a esperança de cura é um sentimento permanente, ainda que os pais conheçam a gravidade da doença, e que é remota a possibilidade de recuperação".

As mães relataram, também, expectativas negativas e ansiedade/insegurança relacionadas ao futuro de seus filhos. Ao mesmo tempo em que crêem na melhora verbalizam sentimentos que expressam a dúvida, medo e temor do futuro, desde perda $\mathrm{e}$ morte do filho ate mesmo como esses irão sobreviver frente à falta delas próprias:

Negativas: "Tínhamos medo e temos de que ele (criança) não sobreviva..." (F19 -

Hidrocefalia)

As expectativas Negativas configuraram-se com a descrença em relação ao futuro do filho como promissor. As entrevistadas demostraram desencanto quanto ao futuro, ao tratamento, à cura, etc.

Essa expectativa vem atrelada ao sentimento de dúvida que bloqueia os pais que não percebem que cada criança tem um ritmo diferente de maturação e desenvolvimento. Além disso, a ansiedade decorrente do desenvolvimento retardatário faz com que não dêem atenção ao que já foi obtido. Assim, se a criança fala, os pais preocupam-se pois ainda não anda.

Ansiedade/ insegurança: "aí é que tá o meu medo... Tenho medo de que ela (filha) venha a depender da gente para tudo..." (F17 - Síndrome de Down).

A ansiedade é uma ânsia, um estado afetivo caracterizado por um sentimento de insegurança. É a condição daquele que não tem segurança, confiança ou garantia. As mães relataram a preocupação com o futuro de seus filhos deficientes frente à morte dos progenitores principalmente pelo fato desses filhos serem relativamente dependentes. Sentem-se insegu- 
ras pois não sabem quem poderia estar assumindo os cuidados de seus filhos quando estiverem ausentes. Assim o envelhecimento dos pais passa a ser vivificado como uma fase de sofrimento, no qual os temores novos juntam-se aos antigos.

Futura descendência: "estou com esperanças de que encontrem alguma coisa, porque isso vai responder o porque aconteceu com as crianças. Vai me tranqüilizar. Primeiro quero saber o motivo, depois planejar nova gravidez... Se o exame não der nada vai permanecer na incógnita do porquê, não tenho, não arrisco... nem se for de $5 \%$ não engravido."

(F14 - Futura Descendência).

As mães que vieram ao Aconselhamento por terem tido história de abortos de repetição ou natimorfos, aqui definida como Futura Descendência, demonstraram em relação ao futuro a vontade de esclarecer o diagnóstico, as dúvidas sobre as causas diagnósticas e a resposta sobre a possibilidade de engravidar novamente. Tendo a causa dos abortos de recorrência definida, tentar-a gravidez de uma maneira mais tranqüila. Petean (1995) também observou em seus dados que a decisão de uma nova gravidez está condicionada ao risco de repetição.

Observou-se que esses casais nutrem o sentimento de esperança na resposta negativa de algum risco para futuras gestações por parte dos profissionais, crendo sempre realizar o sonho de serem pais.

\section{Considerações Finais}

A amostra constituir-se somente de mães é fato natural pois na população aqui representada, a um dos membros do casal, quase sempre à mãe, é atribuída a função de "cuidar" da criança, principalmente nas questões relacionadas à saúde $\mathrm{e}$ educação. Esses dados corroboram o de Pina-Neto (1983) que também encontrou maior atenção das mães ao lidar com os filhos.

As reações das mães, num primeiro momento foram de choque, tristeza, revolta, resignação, culpa, bem como busca de ajuda para o filho. Essas reações são as comumente encontradas na literatura que abarca a questão da defíciência. Porém nesse estudo diferentes síndromes estiveram presentes, o que leva a supor que, independentemente da problemática, as reações manifestadas são as mesmas.

$O$ fato de grande parte das mães explicarem a causa do problema com base em argumentos não científicos leva a supor que a maioria das pessoas possue dificuldade em compreender os mecanismos causadores da deficiência. Assim, as crendices populares, ou dogmas religiosos que passam de geração à geração tornam-se mais compreensíveis e confortadoras para elas.

Essa observação remete-se à caracterização da amostra. A carência de argumentos tidos como científicos pode relacionar-se com o fato das mães da amostra possuírem baixo nível cultura. Salvo explicações tidas como Científicas Corretas, as mães demonstram dificuldade em estar assimilando os argumentos médicos em detrimento de suas próprias justificativas reais e palpáveis, porém nem sempre verdadeiras em termos científicos.

Esta foi uma discussão também apresentada por Pina-Neto (1983). Segundo o autor os fundamentos de explicação que os pais usam depende do estado social a que pertencem, deixando claro as fronteiras de penetração da Medicina Científica junto às camadas populares. Conclui que provavelmente a baixa escolaridade $\mathrm{e}$ a distância social entre as pessoas das camadas populares e os agentes do processo de Aconselhamento Genético devem ser os principais responsáveis pela dificuldade de assimilação das princípios científicos pela maioria das pessoas.

No entanto, como Regen e cols (1993), ressalta-se aqui a necessidade de saber porquê o filho é portador de tal ou qual anomalia como forma de aliviar certos conflitos relacionados à culpa, inferioridade, vergonha, confusão e raiva.

No estudo sobre representação das causas das doenças, observou-se que ao definir a doença os familiares pautam-se nos sintomas apresentados e a partir daí revelam suas representações sobre o mal, delimitando-o, bem como suas relações e seu significado, excluindo das suas representações a gravidade da doença (Crepaldi, 1999)

Observou-se que um dos mecanismos de defesa mais utilizados pelas mães foi a negação, manifestada de forma explícita ou implícita. Utilizaram-se desse mecanismo como forma de minimizar ou encobrir a problemática da criança no intuito de conseguir um maior tempo para se 
reestruturarem. Como afirma Buscaglia (1993) acruel dolorosa realidade de ser subitamente presenteado com uma criança portadora de uma deficiência permanente e o sentimento de total incapacidade para mudar a situação não são coisas fáceis de aceitar. Portanto, é normal, a princípio questionar, culpar, rejeitar e até mesmo odiar a si mesmos e a criança. E normal tentar evitar a dor, expulsando-a da mente, fugindo ou disfarçando, negando a sua existência e fantasiando seu fim.

Sabendo que um aspecto essencial para a evolução da criança é a conduta dos pais como detentora de benefícios e prejuízos no processo de desenvolvimento, em relação às expectativas ao futuro dos filhos as mães demonstraram-se preocupadas com o desenvolvimento geral desse e com a perspectiva de cura. A busca de cura mostrouse como uma necessidade normal dos pais que permanece presente independente do tipo de deficiência ou da compreensão destes sobre o diagnóstico. Crepaldi (1995) também conclui em seu estudo que a esperança de cura é um sentimento permanente, ainda que os pais conheçam a gravidade da doença e que é remota a possibilidade de recuperação.

Em função aos pontos aqui salientados considera-se fundamental que os profissionais envolvidos com a questão da deficiência tomem conhecimento não só das condições emocionais dos pais, mas também que conheçam suas expectativas e principalmente conheçam quais são as explicações que estão dando para o problema.

Outro fator a ser salientado é o da adequação da linguagem dos profissionais, oferecendo aos pais informações claras e objetivas, permitindo-lhes uma melhor compreensão dos fatos. Desta forma, acreditase que o profissional efetivamente estará trabalhando com a realidade de cada família, contribuindo para a sua reestruturação.

\section{Referências Bibliográficas:}

\section{Amaral, L. A. (1995). Conhecendo a Deficiência (em companhia de Hércules) São Paulo: Robe Edi- torial.}

Ardore, M.; Regen, M. \& Hoffmann, V. M. B. (1998).
Eu Tenho um Irmão Deficiente... Vamos Conversar Sobre Isso? São Paulo: Edições Paulinas e APAE/SP.

Biasoli-Alves, Z. M. M. \& Dias, M. H. G. F. S. (1992). Análise Qualitativa da Entrevista: Uma Proposta. Paidéia 2, 61-69.

Boyd, D. (1950). As Três Fases. (M. A. V. Xavier, Trad). New Jersey: National Association for Retarded Children. Livreto.

Brunhara, F. C. R. \& Petean, E. B. L. (1998). Expectativas dos Pais Quanto ao Desenvolvimento de seus Filhos Portadores de Deficiência. Anais do II Congresso Brasileiro de Psicologia do Desenvolvimento. Gramado, R.S.

Buscaglia, L. (1993) Os deficientes e seus pais. Um desafio ao aconselhamento. Rio de janeiro: Editora Record.

Cannel, C. F. \& Kahn, R. L. (1974). Coleta de dados por entrevista. In: Festinguer, L. \& Kats, D. A A pesquisa da Psicologia Social. Rio de Janeiro: E.F.G.V.

Crepaldi, M. A. (1999). Hospitalização na Infância: representações sociais da familia sobre a doença e a hospitalização de seus filhos. Taubaté Cabral Editora Universitária.

Drotar, D.; Baskiwcs, A.; Irvin, N.; Kennel, J. E Klaus, M. A. (1975). Adaptação dos pais ao nascimento de um bebê com malformação congênita: um modelo hipotético. (M. A. V. Xavier, Trad). Pediatrics 56(5): 710-716.

Faber, B. (1972). Effects of a Several Retarded Child on the Family. In: E. P. Trapp e P. Himelstein (Eds). Readings on the exceptional Child: Research and Theory. Appleton-Century-Crofts. New York

Ferreira, A. B. H. (1988). Novo Dicionário Aurélio. Rio de Janeiro: Editora Nova Fronteira.

McCollum, A. T. (1984). Gireving Over the Lost Dream. Excepcional Parent 14: 9-12

Miller, H. (1995). Ninguém é Perfeito: Vivendo e crescendo com crianças que têm necessidades especiais. Campinas: Papirus

Minayo, M. C. S. (1993). O desafio do conhecimen- 
to: pesquisa qualitativa em Psicologia. São Paulo - Rio de Janeiro: Hucitec - Abrasco.

Omote, S. (1980).Reações de Mães de Deficientes Mentais ao Reconhecimento da Condição dos Filhos Afetados: Um estudo Psicológico. Dissertação de Mestrado apresentada ao Instituto de Psicologia da Universidade de São Paulo, São Paulo.

Petean, E.B.L. (1995). Avaliação Qualitativa dos Aspectos Psicológicos do Aconselhamento Genético Através do Estudo Prospectivo do Atendimento das Famílias. Tese de Doutorado apresentada junto ao Programa de Pós-Graduação em Saúde Mental da Faculdade de Ciências Médicas da UNICAMP. Campinas.

Petean, E. B. L. \& Pina-Neto, J. M. (1998). Investigação em aconselhamento genético: Impacto da primeira notícia - a reação dos pais à deficiência. Medicina31: 288-295

Pina-Neto, J. M. (1983) Aconselhamento genético: avaliação dos resultados através do seguimento tardio das famílias, Tese de Livre-Docência apresentada à Faculdade de Medicina de Ribeirão Preto da Universidade de São Paulo, Ribeirão Preto.

Regen, M.; Ardore, M. \& Hoffmann, V. M. B. (1993). Mães e Filhos Especiais: Relato de experiência com grupos de Mães de crianças com deficiência. Brasília: Coordenadoria Nacional para Integração da Pessoa Portadora de Deficiência - CORDE.

Soifer, R. (1980). Psicologia da Gravidez, Parto e Puerpério. (Ilka Valle de Carvalho, Trad.). Porto Alegre: Artes Médicas.

Valle, E. R. M. (1997). Câncer Infantil: Compreender e Agir. Campinas, S.P.: Editorial Psy.

Vash, C. L. (1988).Enfrentando a Deficiência: a Manifestação, a Psicologia, a Reabilitação. Coleção Novos Umbrais. São Paulo: Pioneira. 